\title{
Effects of a Protein-Enriched Crude Lysate from Chlorella Sp. Against Acetaminophen-Induced Liver Injury
}

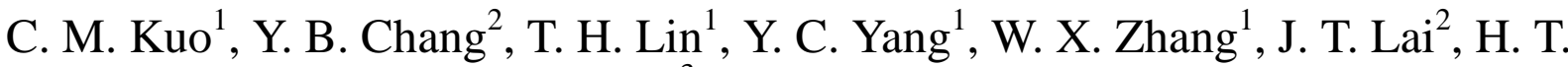 \\ $\mathrm{Wu}^{3}$, C. S. Lin $1, *$ \\ ${ }^{I}$ (Department of Biological Science and Technology, National Chiao Tung University, Hsinchu, Taiwan) \\ ${ }^{2}$ (Bioresource Collection and Research Center, Food Industry Research and Development Institute, Hsinchu, \\ Taiwan) \\ ${ }_{3}^{3}$ (Department of BioAgricultural Science, National Chia Yi University, Chiayi city 600, Taiwan)
}

\begin{abstract}
The effect of crude lysate of Chlorella sp. (CLC) on acetaminophen (APAP)-induced liver injury in male ICR mice was investigated. The CLC is a protein-enriched powder containing around $65 \%$ of microalgal proteins. There were no hepatotoxicity and renal toxicity detected in the mice fed with the feed containing CLC with a much high level of 10\% for 28 days. The hepatoprotective function of CLC was determined in a mouse model of APAP-induced liver injury. Each CLC supplementation $(1,2.5$, and 5\% CLC) groups could significantly alleviate the increased serum glutamic oxaloacetic transaminase (GOT) and glutamic pyruvic transaminase (GPT), and hepatic superoxide dismutase (SOD), catalase (CAT) and oxidative damage in the APAP-treated mice. The hepatoprotective effects in the CLC supplementation groups were comparable with the mouse group treated with silymarin, a drug for liver injury. Our results indicate the CLC containing molecules that is potential as candidate for the prevention of chemical-induced liver damage.
\end{abstract}

Keywords: acetaminophen, antioxidative effect, crude lysate of Chlorella sp., hepatoprotective function

\section{Introduction}

Microalgae are usually used as additive in food to enhance the nutrient of food and/or improve the health of humans and animals because of their chemical composition and bioactive molecules. The high protein content of microalgae is the major reason for the untraditional source of protein [1]. Moreover, the amino acids of microalgae which could synthesize essential amino acid to humans and animals compares favorably with that of other food proteins [2]. Furthermore, there are many valuable antioxidants in microalgae, e.g., chlorophyll, carotenoids, astaxanthin, lutein and phycobiliproteins[3, 4]. Chlorella sp., a type of unicellular green algae, has been a popular food supplements or health food worldwide [3]. Taiwan is one of the major countries to produce Chlorella-related productions. The world annual sales of Chlorella sp. are in excess of US\$ 38 billion [5]. It has been reported to have certain beneficial physiological effects by Chlorella sp. supplementation, such as antihypertensive [6], antioxidative [7], hypocholesterolemic [8] and antitumor activities [9] in animal and human studies. However, the hepatoprotective activity of extract derived from Chlorella sp. is not extensively studied [10]. Acetaminophen, or N-acetyl-para-amino-phenol (APAP), is the widely used analgesic antipyretic drug, though considered a safe drug; it causes hepatic necrosis and renal failure when given in high doses [11]. Increasing acute liver failure cases attributed to APAP use during last two decades have been reported [12]. Oxidative stress was reported to play a fundamental role in the pathogenesis of APAP-induced liver damage [13]. In the present study, the crude lysate of Chlorella sp. powder enriched in protein and antioxidants, i.e., CLC, was prepared and used as diet supplement to investigate the bioactivity functions on hepatoprotection. In agreement with previous studies[14, 15], significant liver injury in the mice administrated with APAP was found and the liver injury could be recovered by CLC supplementation, even only $1 \%$ of CLC added in the diet for mice. To overcome APAP-induced hepatic oxidative damage, the search for new bioactive products with antioxidant activity is necessary. The present study was undertaken to evaluate the protective effect of the protein and antioxidants-enriched crude lysate from Chlorella sp. against APAP-induced liver injury in a mouse model.

\subsection{Microalgal strain and chemicals}

\section{Materials And Methods}

The fresh water microalga Chlorella sp. was originally obtained from the collection of Taiwan Fisheries Research Institute (Pingtung, Taiwan). The fresh water microalgal culture medium has following composition (per liter): including $1.25 \mathrm{~g} \mathrm{KNO}_{3}, 1.25 \mathrm{~g} \mathrm{KH}_{2} \mathrm{PO}_{4}, 1 \mathrm{~g} \mathrm{MgSO}_{4} \cdot 7 \mathrm{H}_{2} \mathrm{O}, 83.5 \mathrm{mg} \mathrm{CaCl}{ }_{2} \cdot 2 \mathrm{H}_{2} \mathrm{O}$, $0.1142 \mathrm{~g} \mathrm{H}_{3} \mathrm{BO}_{3}, 49.8 \mathrm{mg} \mathrm{FeSO}{ }_{4} \cdot 7 \mathrm{H}_{2} \mathrm{O}, 88.2 \mathrm{mg} \mathrm{ZnSO}{ }_{4} \cdot 7 \mathrm{H}_{2} \mathrm{O}, 14.4 \mathrm{mg} \mathrm{MnCl_{2 }} \cdot 4 \mathrm{H}_{2} \mathrm{O}, 15.7 \mathrm{mg} \mathrm{CuSO}{ }_{4} \cdot 5 \mathrm{H}_{2} \mathrm{O}$, $7.1 \mathrm{mg} \mathrm{Na} 2 \mathrm{MoO}_{4}, 4.9 \mathrm{mg} \mathrm{Co}\left(\mathrm{NO}_{3}\right)_{2} \cdot 6 \mathrm{H}_{2} \mathrm{O}$. The initial $\mathrm{pH}$ of the initial culture medium was adjusted to 6 by $5 \mathrm{~N}$ 
$\mathrm{NaOH}$ [16]. All of chemicals were purchased from Sigma-Aldrich (St. Louis, MO, USA) or Showa Corp. (Gyoda, Saitama, Japan).APAP and silymarin were purchased from Sigma-Aldrich. All the diagnostic kits assaying hepatic function tests, the levels of lipid peroxidation and antioxidants were obtained from Cayman Chemical Company (Ann Arbor, MI, USA). All of the chemicals were of analytical grade.

\subsection{Chlorella sp. cultivation}

Microalga Chlorella sp. was cultured in an autotrophic outdoor cultivation in an outdoor vertical photobioreactor array (total culture volume is 2,000 L) [17]with a semi-continuous culture operation from September to December, 2016. The microalgal cultures were aerated with $2 \% \mathrm{CO}_{2}$ at day light and with air at night. The microalgal cultures were aerated continuously with bubbling gas from the bottom of photobioreactor with an aeration rate of $0.2 \mathrm{vvm}$ (volume gas per volume broth per min). The microalgal biomass productivity could reach about $0.6 \mathrm{~g}$ (dry matter)/(L·day).

\subsection{The process of Chlorella sp. biomass}

The microalgae were harvested by continuous-flow centrifugation (Alfa Laval, Lund, Sweden) up to about $10 \%$ dry matter in the slurry and then submitted to disruption in a ultrasonic extraction apparatus (Yenchen, Taoyuan, Taiwan) under ultrasonic power $500 \mathrm{~W}$ and temperature of microalgal slurry $25-30^{\circ} \mathrm{C}$ by a circulated water cooling jacket with continuous ultrasonication for $6 \mathrm{~h}$ to make sure the disruption rate being up to $80 \%$. Finally, the microalgal slurry was centrifuged to remove debris and undisrupted cells, and then dried in a spray dryer (INORA, Taichung, Taiwan) at $180-200^{\circ} \mathrm{C}$ inlet and $90-100^{\circ} \mathrm{C}$ outlet temperature. The crude lysate of Chlorella sp. (CLC) powder thus obtained (moisture content about 6.8\%) was preserved for further determination and use.

\subsection{Chemical analysis}

Total nitrogen, total fiber and ash were analyzed according to AOAC [18] approved methods. Crude protein content was calculated using a conversion factor of 6.25. Total soluble sugars were estimated colorimetrically by the phenol-sulfuric acid method using a standard curve of glucose [19], and total lipids were measured according to Kochert [20]. Pigments were determined in methanolic extracts according to Wellburn [21]. Nucleic acids were measured as described by Rut [22].

\subsection{Animal experiment}

Male ICR mice (4 weeks old; $20.3 \pm 2.2 \mathrm{~g}$ ) were obtained from National Laboratory Animal Center (NLAC, Taipei, Taiwan) and were allowed to quarantine and acclimate for a week prior to experimentation. The animals were handled under standard laboratory conditions of a $12 \mathrm{~h} \mathrm{light/dark} \mathrm{cycle} \mathrm{in} \mathrm{a} \mathrm{temperature} \mathrm{and}$ humidity controlled room (at $22 \pm 2{ }^{\circ} \mathrm{C}$ and $60 \pm 5 \%$ relatively humidity). Food (normal chow diet) and water were available ad libitum. Institutional Animal Care and Use Committee of National Chiao Tung University (Taiwan) approved the protocols for the animal study, and the animals were cared for in accordance with the institutional ethical guideline. The animals were randomly divided into 6 groups with each consisting of 6 mice. Groups and treatments of the mice were listed in Table 1. Group Normal served as normal control and was given phosphate buffered saline (PBS) buffer as placebo by intraperitoneal injection (IP). For inducing hepatotoxicity (in vivo), the animals of Group NC, PC, 1, 2.5 and 5\% CLC were administered $200 \mathrm{mg} / \mathrm{kg}$ body weight of APAP dissolved in PBS buffer by IP twice a week for a period of 4 weeks. After APAP intoxication, Group NC served as negative control APAP. Group PC served as positive control and was given $0.1 \%$ silymarin $(\mathrm{w} / \mathrm{w})$ daily mixed in food ad libitum for a period of 4 weeks. Group 1, 2.5 and 5\% CLC were given the CLC in feed at contents of 1, 2.5 and $5 \%(\mathrm{w} / \mathrm{w})$ ad libitum for a period of 4 weeks, respectively. At the end of the experiment, the animals were sacrificed. Blood samples were centrifuged to obtain serum at 3,000 $\times g$ for 15 min at $4^{\circ} \mathrm{C}$. Liver samples were dissected out and washed immediately with ice phosphate buffered saline ( $\mathrm{pH}$ 7.4) to remove as much blood as possible. A piece of the liver sample was fixed in $10 \%$ formalin for histopathological examination. The remnants of the livers were immediately stored at $-80^{\circ} \mathrm{C}$ until the experiment.

Table 1. Groups and treatments of the experimental ICR mice.

\begin{tabular}{|l|l|l|l|}
\hline Group & Short name of group & Treatment & Diet \\
\hline Normal control & Normal $^{\mathrm{a}}$ & PBS buffer & Chow diet \\
\hline $\begin{array}{l}\text { Acetaminophen } \\
\text { (negative control) }\end{array}$ & $\mathrm{NC}^{\mathrm{b}}$ & APAP & Chow diet \\
\hline $\begin{array}{l}0.1 \% \text { silymarin } \\
\text { (positive control) }\end{array}$ & $\mathrm{PC}^{\mathrm{c}}$ & APAP & Chow diet containing 0.1\% silymarin $(\mathrm{w} / \mathrm{w})$ \\
\hline $1 \%$ crude lysate of Chlorella $\mathrm{sp}$. & $1 \% \mathrm{CLC}^{\mathrm{d}}$ & APAP & Chow diet containing 1\%CLC $(\mathrm{w} / \mathrm{w})$ \\
\hline $2.5 \%$ crude lysate of Chlorella $\mathrm{sp}$. & $2.5 \% \mathrm{CLC}^{\mathrm{e}}$ & APAP & Chow diet containing $2.5 \% \mathrm{CLC}(\mathrm{w} / \mathrm{w})$ \\
\hline $5 \%$ crude lysate of Chlorella $\mathrm{sp}$. & $5 \% \mathrm{CLC}^{\mathrm{f}}$ & APAP & Chow diet containing 5\%CLC $(\mathrm{w} / \mathrm{w})$ \\
\hline
\end{tabular}

${ }^{a}$ Group Normal served as normal control with feeding chow diet and was given PBS buffer as placebo by IP twice a week for a period of 4 weeks. 
${ }^{\mathrm{b}}$ Group NC served as negative control APAP with feeding chow diet and was given $200 \mathrm{mg} / \mathrm{kg}$ body weight of APAP dissolved in PBS buffer by IP twice a week for a period of 4 weeks.

${ }^{c}$ Group PC served as positive control $0.1 \%$ silymarin with feeding chow diet containing $0.1 \%$ silymarin (w/w) and was given $200 \mathrm{mg} / \mathrm{kg}$ body weight of APAP dissolved in PBS buffer by IP twice a week for a period of 4 weeks.

d, e,f Group 1, 2.5 and 5\% CLC of mice were fed chow diet containing 1, 2.5 and 5\% CLC (w/w) individually and was given $200 \mathrm{mg} / \mathrm{kg}$ body weight of APAP dissolved in PBS buffer by IP twice a week for a period of 4 weeks, respectively.

\subsection{Homogenate preparation}

Liver tissues were homogenized with exact buffer according to the protocols of commercially available kits, and centrifuged at $10,000 \times g$ for $30 \mathrm{~min}$ in a high-speed centrifuge (HanilBioMed, Gwangju, Korea) at $4^{\circ} \mathrm{C}$. The supernatants were collected to determine the activity of superoxide dismutase (SOD), catalase (CAT) and the malondialdehyde (MDA) content.

\subsection{Assay of blood biochemistry}

The activities of glutamic oxaloacetic transaminase (GOT), glutamic pyruvic transaminase (GPT), blood urea nitrogen (BUN) and albumin (ALB) in serum were measured to evaluate hepatoxicity and renal toxicity. An autoanalyzer (FUJIFILM, Kanagawa, Japan) was used in the experiments.

\subsection{Determination of hepatic SOD and CAT activity}

SOD was measured according to the protocol of commercially available kit (Cayman Chemical Company). SOD activity was evaluated by utilizing a tetrazolium salt for detection of superoxide radicals generated by xanthine oxidase and hypoxanthine. One unit of SOD is defined as the amount of enzyme needed to exhibit $50 \%$ dismutation of the superoxide radical. SOD activity is standardized using the cytochrome c and xanthine oxidase coupled assay.CAT activity was measured by the decomposition of $\mathrm{H}_{2} \mathrm{O}_{2}$ according to the Aebi[23]. The final reaction mixture comprised $10 \mathrm{mM} \mathrm{H}_{2} \mathrm{O}_{2}$ in $50 \mathrm{mM}$ phosphate buffer at $\mathrm{pH}$ 7.0. The decomposition of $\mathrm{H}_{2} \mathrm{O}_{2}$ was followed by spectrophotometry at 240nm. CAT activity is expressed in $\mathrm{k} / \mathrm{mg}$ protein, and the equation showed as follows:

$\mathrm{k} / \mathrm{mg}$ protein $=\left[2.3 /\left(\mathrm{t}_{2}-\mathrm{t}_{1}\right)\right] \times \log \left(\mathrm{A}_{1} / \mathrm{A}_{2}\right)$

where $\mathrm{k}$ is the first-order reaction rate constant, $\mathrm{t}$ is the time over which the decrease of $\mathrm{H}_{2} \mathrm{O}_{2}$ due to CAT activity was measured $30 \mathrm{~s}$, and $\mathrm{A}_{1} / \mathrm{A}_{2}$ is the optical density at times 0 and $30 \mathrm{~s}$, respectively.

\subsection{Determination of hepatic lipid peroxidation intermediate}

The MDA content, a measure of lipid peroxidation, was assayed in the form of thiobarbituric acid-reactive substances. Briefly, a volume of $0.5 \mathrm{~mL}$ of liver homogenate was mixed with $3 \mathrm{~mL}$ of $1 \% \mathrm{H}_{3} \mathrm{PO}_{4}$ $(\mathrm{v} / \mathrm{v})$ and $1 \mathrm{~mL}$ of $0.6 \%$ thiobarbituric acid (TBA, w/v) and then heated to and maintained at $100^{\circ} \mathrm{C}$ for $40 \mathrm{~min}$. The samples were allowed to reach room temperature and $2 \mathrm{~mL}$ of butanol was added. After shaking vigorously with the vortex, the butanolic phase was obtained by centrifugation at 3,000 $\times g$ for 10 min to determinate the absorbance at $535 \mathrm{~nm}$.

\subsection{Statistics}

Data were compared with one-way analysis of variance (ANOVA) test to evaluate differences among multiple groups. All results are expressed as the mean \pm standard deviation (SD). Differences were considered statistically significant when $p<0.05$. Statistical analysis was performed using statistical soft-ware (SPSS, Chicago, IL, USA).

\subsection{Preparation of the crude lysate of Chlorella sp.}

\section{Results And Discussion}

Chemical composition of Chlorella sp. biomass and its CLC were shown and compared in Table 2. The main feature was their abundant protein content (50-55\%). The crude protein, soluble carbohydrates, total fiber, fat, ash and nucleic acids obtained in the CLC biomass were $63.7 \pm 2.1,17.3 \pm 1.1,4.5 \pm 0.6,3.4 \pm 0.6,5.6 \pm 0.7$ and $1.4 \pm 0.2 \mathrm{~g} / 100 \mathrm{~g}$ individually after ultrasonic extraction. Especially the crude protein of ultrasonic-extracted CLC biomass was 1.2 times higher than that of non-extracted biomass. Besides, the CLC also contains a number of biologically active compounds as chlorophylls $(2,094 \pm 166 \mathrm{mg} / 100 \mathrm{~g})$ and carotenoids $(211 \pm 20 \mathrm{mg} / 100 \mathrm{~g})$, these compounds have the potential function of free radicles scavenging, i.e., antioxidative activity. The chlorophylls and carotenoids of CLC biomass both were increased 1.5 folds compared with that of non-extracted biomass.

Table 2. Chemical composition of Chlorella sp. biomass and its crude lysate (CLC). \begin{tabular}{|l|l|l|}
\hline Constituent (g/ 100 g) & Non-extracted biomass $^{\mathrm{a}}$ & Ultrasonic-extracted biomass $^{\mathrm{b}}$ \\
\hline
\end{tabular} 


\begin{tabular}{|l|l|l|l|}
\hline Crude protein $(\mathrm{N} \times 6.25)$ & $53.6 \pm 2.3$ & $63.7 \pm 2.1$ \\
\hline Carbohydrates & $16.7 \pm 1.0$ & $17.3 \pm 1.1$ \\
\hline Fiber & $8.5 \pm 1.0$ & $4.5 \pm 0.6$ \\
\hline Fat & $6.6 \pm 0.8$ & $3.4 \pm 0.6$ \\
\hline Ash & $6.5 \pm 0.7$ & $5.6 \pm 0.7$ \\
\hline Nucleic acids & $5.5 \pm 0.6$ & $1.4 \pm 0.2$ \\
\hline Others & $2.6 \pm 0.6$ & $4.1 \pm 0.8$ & \\
\hline Pigments (mg/100g) & & & \\
\hline Chlorophylls & $1,394 \pm 148$ & $2,094 \pm 166$ & \\
\hline Carotenoid & $130 \pm 16$ & $211 \pm 20$ \\
\hline
\end{tabular}

Each data indicates the mean \pm SD from three independent determinations.

${ }^{a}$ The Chlorella sp. biomass was harvested and spray-dried without extraction.

${ }^{\mathrm{b}}$ The CLC was harvested and spray-dried with ultrasonic extraction.

\subsection{Feeding toxicity of $C L C$}

The ICR mice were fed with the chow diet containing $0,1,5$ and $10 \%$ (w/w) of CLC to test feeding toxicity. After 28 days, the ICR mice were sacrificed to determine the serum GPT and GOT activities for evaluating the liver function and serum BUN and ALB activities for evaluating the kidney function. The final body weights of the mice, which were fed with the chow diet containing $0,1,5$ and $10 \%$ (w/w) of CLC, were 40.3 $\pm 2.2,40.9 \pm 2.0,41.7 \pm 2.3$ and $41.3 \pm 2.6 \mathrm{~g}$, respectively. As shown in Fig. 1, all of the average serum GPT, GOT, BUN and ALB levels in Group 1, 5, 10\% CLC were no significant differences between the Group Normal. These results indicate that mice fed with the protein-enriched CLCup to a dose level of $10 \%(\mathrm{w} / \mathrm{w})$ were considered as safe, and none hepatic and renal toxicity induced. Hence, 1, 2.5 and 5\% CLC in feed were selected to evaluate the effect of Chlorella sp. supplementation against APAP-induced liver injury in the study.

(A) GOT and GPT

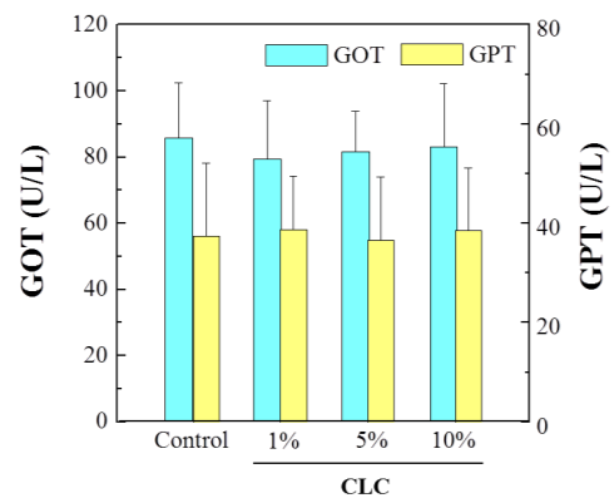

(B) BUN and ALB

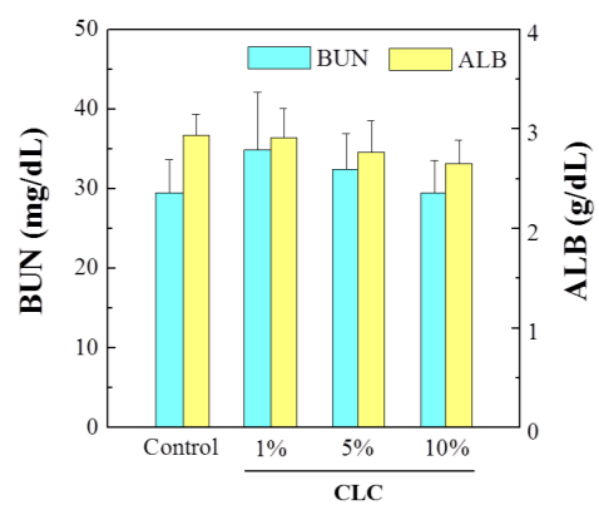

Figure 1. Index of liver function of the ICR mice supplement with CLC for toxicity test.The ICR mice were fed with containing 1,5 and $10 \%$ of CLC (w/w) and without containing CLC as control for 28 days. The ICR mice were sacrificed after 28 days to determine the GOT and GPT (A), and BUN and ALB (B) activity in serum. All of the values were expressed as the mean \pm SD from 6 mice of each group.

\subsection{Effect of CLC supplementation on liver marker enzymes in serum}

Table 1 shows the detail information of the experimental animal groups. As shown in Fig. 2, the mice challenged with APAP (Group NC) for 4 weeks showed significantly increased serum GOT and GPT activities compared with those in the sham control (Group Normal) (166 \pm 46 vs. $62 \pm 12 \mathrm{U} / \mathrm{L}$ for GOT and $118 \pm 39$ vs. 30 $\pm 10 \mathrm{U} / \mathrm{L}$ for GPT; $p<0.05$ ), indicating that APAP induced the hepatotoxicity. Both of silymarin administration (Group PC) and CLC supplementation could reduce the increases of serum GOT and GPT induced by APAP treatment. Serum GOP and GPT levels in Group PC, Group 1, 2.5 and 5\% CLC were 77 $\pm 15,86 \pm 9,78 \pm 12$ and $71 \pm 8 \mathrm{U} / \mathrm{L}$, and $44 \pm 11,52 \pm 6,48 \pm 11$ and $42 \pm 10 \mathrm{U} / \mathrm{L}$, respectively.GOP and GPT levels among these groups were similar without significant difference. However, Group PC, Group 1, 2.5 and 5\% CLC were significantly reduced serum GOT and GPT activities, compared with the APAP-treated group $(p<0.05)$. These results suggested that the CLC was no dose-dependent protective effect against APAP-induced hepatotoxicity, but the CLC may provide the liver protection caused by APAP-induced. Similar results in previous study [24], the increase of serum GOT and GPT activities in APAP-intoxicated mice was significantly alleviated in diets containing6 and 9\% Spirulina platensis. 


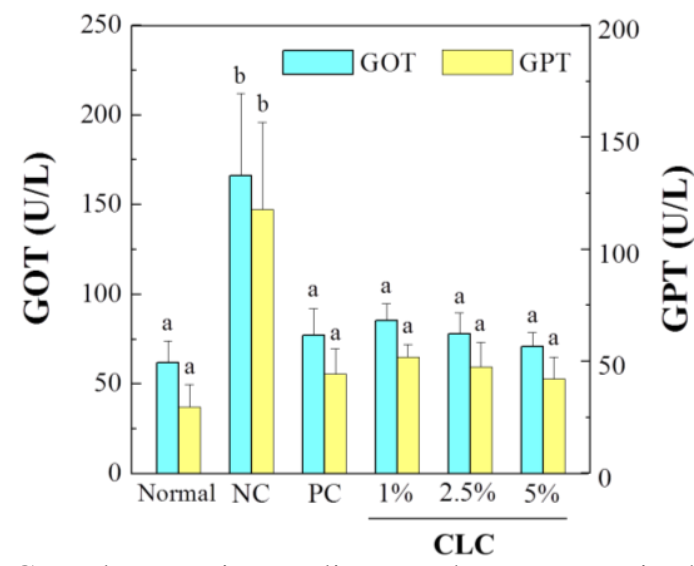

Figure 2.Effect of CLCsupplementation on liver marker enzymes in the serum of mice administrated with APAP. The Group NC, PC, 1, 2.5 and 5\% CLC were administrated with $200 \mathrm{mg} / \mathrm{kg}$ APAP and the Group Normal was administrated with PBS as placebo twice a week for 4 weeks. The PC was fed with the chow diet containing $0.1 \%$ silymarin (w/w). The Group $1,2.5$ and $5 \%$ CLC were fed with the chow diet containing $1,2.5$ and $5 \%$ ofCLC (w/w), respectively. All the groups were sacrificed after 4 weeks to sample the blood via cardiac puncture to determine the GPT and GOT activities in serum. All of the values were expressed as the mean \pm SD from 6 mice of each group. Letters mean there are significant differences between each group $(p<0.05)$.

\subsection{Effect of CLC supplementation on hepatic antioxidative enzymes activity}

Results pertaining to the activities of hepatic antioxidative enzymes, SOD and CAT, were presented in Fig. 3. APAP administration would induce oxidative stress in liver and resulted in the decreased hepatic SOD and CAT activities. The hepatic SOD and CAT activities in Group NC (APAP-treated only) were $144 \pm 17 \mathrm{U} / \mathrm{mg}$ protein and $0.192 \pm 0.091 \mathrm{k} / \mathrm{mg}$ protein, respectively. Both levels were significantly lower than those in Group Normal, $252 \pm 3 \mathrm{U} / \mathrm{mg}$ protein in SOD and $0.618 \pm 0.086 \mathrm{k} / \mathrm{mg}$ protein in CAT. In Group PC (APAP-treated plus silymarin administration), the hepatic SOD and CAT activities was $233 \pm 11 \mathrm{U} / \mathrm{mg}$ protein and $0.757 \pm 0.151$ $\mathrm{k} / \mathrm{mg}$ protein, respectively. Both SOD and CAT activities in Group 1\% CLC $(226 \pm 9 \mathrm{U} / \mathrm{mg}$ protein and $0.648 \pm$ $0.177 \mathrm{k} / \mathrm{mg}$ protein) and Group $2.5 \%$ CLC $(235 \pm 14 \mathrm{U} / \mathrm{mg}$ protein and $0.747 \pm 0.202 \mathrm{k} / \mathrm{mg}$ protein) were comparable with those determined in Group PC. Group 5\% CLC had $243 \pm 17 \mathrm{U} / \mathrm{mg}$ protein in SOD and 0.786 $\pm 0.117 \mathrm{k} / \mathrm{mg}$ protein in CAT. Both values were higher than those detected in Group PC, Group 1\% CLC and Group 2.5\% CLC; however, the differences were insignificant. Based on the SOD and CAT results, it is indicated that the degree of defense for the APAP-induced oxidative stress by CLC were close with that by silymarin administration.It has been reported that oxidative stress plays a fundamental role in the pathogenesis of APAP-induced liver damage $[13,25]$. Our results show that CLC supplementation is responsible for the increased resistance to oxidative stress induced by APAP. CLC supplementation could significantly alleviate the decreased hepatic SOD and CAT activities and increased oxidative liver injury, i.e., hepatic lipid peroxidation, in the APAP-treated mice.Besides, advanced in vitro studies revealed that receptor-interacting protein kinase 1 (RIPK1) inhibition reduces APAP-induced reactive oxygen species (ROS) production, which is one of the main causes of APAP-induced hepatocyte damage[26].

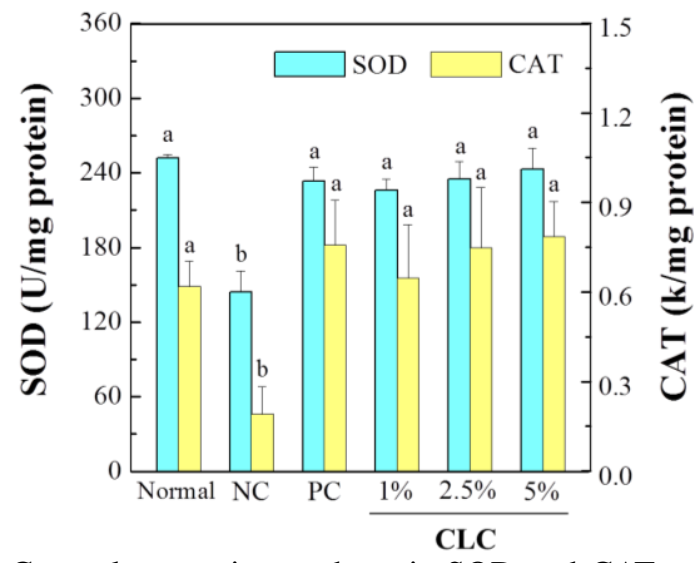

Figure 3.Effect of CLC supplementation on hepatic SOD and CAT activities in the mice with APAP administrated. The Group NC, PC, 1, 2.5 and $5 \%$ CLC were administrated with $200 \mathrm{mg} / \mathrm{kg}$ APAP and the Group Normal was administrated with PBS as placebo twice a week for 4 weeks. The Group PC was fed with chow 
diet containing $0.1 \%$ silymarin (w/w). The Group 1, 2.5 and 5\% CLC were fed with chow diet containing 1, 2.5 and $5 \%$ ofCLC (w/w), respectively. All the mice were sacrificed after 4 weeks and liver was isolated and homogenated for the determinations of hepatic SOD and CAT activities. All of the values were expressed as the mean \pm SD from 6 mice of each group. Letters mean there are significant differences between each group $(p<$ $0.05)$.

\subsection{Effect of CLC supplementation on hepatic lipid peroxidation}

Fig. 4 shows the effect of CLC supplementation on lipid peroxidation against APAP-induced oxidative stress in the mice. Treatment of experimental animals with APAP (Group NC) caused a significant increase in the levels of primary product of lipid peroxidation, MDA, in comparison to the Group Normal $(2.67 \pm 0.84$ vs. $0.33 \pm 0.07 \mathrm{nmol} / \mathrm{mg}$ protein). Supplementation of the mice with CLC showed significant inhibition on the hepatic MDA induced by APAP treatment $(0.72 \pm 0.14,0.63 \pm 0.22$ and $0.47 \pm 0.11 \mathrm{nmol} / \mathrm{mg}$ protein in Group 1 , 2.5 and 5\% CLC, respectively). These eliminated MDA levels by CLC supplementation were statistically similar to the level in group of silymarin treatment (Group PC, $0.69 \pm 0.41 \mathrm{~mol} / \mathrm{mg}$ protein), and correlated with the increase of antioxidant enzymes, such as SOD and CAT.The antioxidant enzymes such as SOD and CAT are related to direct elimination of ROS to prevent and neutralize the free radical-induced damage[10]. In APAP-induced hepatotoxicity, the balance between ROS production and these antioxidant defenses may be lost, oxidative stress results, which through a series of events deregulates the cellular functions leading to hepatic necrosis[15].According to the results in this study, CLC supplementation probablycould reduceoxidative liver injury induced by APAP.

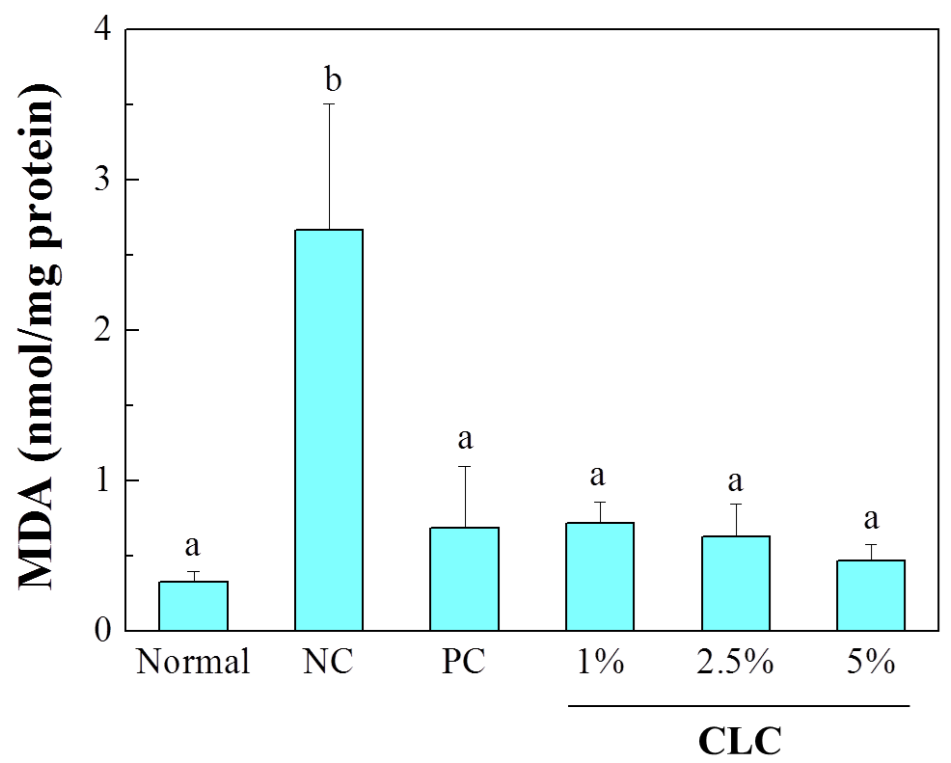

Figure 4.Effect of CLC supplementation on lipid peroxidation in the liver of mice administrated with APAP. The mice in Group NC, PC, 1, 2.5 and 5\% CLC were administrated with $200 \mathrm{mg} / \mathrm{kg}$ APAP and the Group Normal was administrated with PBS as placebo twice a week for 4 weeks. The Group PC was fed with chow diet containing $0.1 \%$ silymarin (w/w). The Group 1, 2.5 and 5\% CLC were fed with chow diet containing 1, 2.5 and 5\% ofCLC (w/w), respectively. After 4 weeks of treatment, all mice were sacrificed and isolated the liver to homogenate for the determination of hepatic lipid peroxidation. All of the values were expressed as the mean \pm SD from 6 mice of each group. Letters mean there are significant differences between each group $(p<0.05)$.

\subsection{Effect of CLC supplementation on histopathological changes in liver}

Histopathological examinations showed that APAP administration (Group NC), compared to the control of the mice received PBS, the liver tissue revealed hepatocyte necrosis with inflammatory cell infiltration. Livers of the mice simultaneously administered with APAP and supplemented with CLC revealed improved liver condition and showed the inflammatory cell infiltration was reduced gradually with increase of CLC dosage. The minimal damage of hepatocyte necrosis was shown in Group 2.5\% CLC and Group 5\% CLC and the situation was comparable to that of mice administrated with silymarin. According to histopathological examinations, severe hepatic lesions induced by APAP were remarkably reduced by the supplementation of CLC, which were in good consistency with the results found in liver marker enzymes in serum and hepatic oxidative stress and lipid peroxidation. 


\section{Conclusions}

In conclusion, crude lysate of Chlorella sp. may have protective functions as ROS scavenger, it can be considering as a potential source of natural antioxidant with hepatoprotective activity. The hepatoprotective effect of Chlorella sp. crude lysate may be also due to the presence of specific peptides and antioxidants in the lysate, which have biological functions, at least including antioxidant activity. Further detailed investigations on this microalgal strain are needed in order to identify and isolate the hepatoprotective components in the extract and to evaluate its use in the treatment of liver disorders.

\section{Acknowledgement}

The work was financially supported by grants MOST 106-3113-E-006-011 from the Ministry of Science and Technology. This work was also supported in part by the Aim for the Top University Program of the National Chiao Tung University and Ministry of Education, Taiwan.

\section{References}

[1] X. Fan, L. Bai, L. Zhu, L. Yang, and X.Zhang,Marine algae-derived bioactive peptides for human nutrition and health,Journal of Agricultural and Food Chemistry, 62(38), 2014, 9211-9222.

[2] J.L. Guil-Guerrero, R. Navarro-Juárez, J.C. López-Martınez, P. Campra-Madrid, and M. Rebolloso-Fuentes, Functional properties of the biomass of three microalgal species,Journal of Food Engineering, 65(4), 2004, 511-517.

[3] M. Plaza,M. Herrero,A. Cifuentes, and E. Ibanez, Innovative natural functional ingredients from microalgae,Journal of Agricultural and Food Chemistry, 57(16),2009, 7159-7170.

[4] F.Ahmed, K. Fanning, M. Netzel, W. Turner, Y. Li, and P.M. Schenk,Profiling of carotenoids and antioxidant capacity of microalgae from subtropical coastal and brackish waters,Food Chemistry, 165, 2014, 300-306.

[5] Z.Yaakob, E. Ali, A. Zainal, M. Mohamad, and M.S. Takriff, An overview: biomolecules from microalgae for animal feed and aquaculture, Journal of Biological Research-Thessaloniki, 21(1),2014, 6-15.

[6] I.C.Sheih, T.J. Fang, and T.K. Wu, Isolation and characterisation of a novel angiotensin I-converting enzyme (ACE) inhibitory peptide from the algae protein waste,Food Chemistry, 115(1),2009, 279-284.

[7] S.C. Ko,D. Kim, and Y.J. Jeon, Protective effect of a novel antioxidative peptide purified from a marine Chlorella ellipsoidea protein against free radical-induced oxidative stress,Food and Chemical Toxicology,50(7),2012, 2294-2302.

[8] J.Y. Cherng, and M.F. Shih, Preventing dyslipidemia by Chlorella pyrenoidosa in rats and hamsters after chronic high fat diet treatment,Life Sciences, 76(26), 2005, 3001-3013.

[9] X.Wang, and X. Zhang, Separation, antitumor activities, and encapsulation of polypeptide from Chlorella pyrenoidosa,Biotechnology Progress, 29(3),2013, 681-687.

[10] L.Li, W. Li, Y.H. Kim, and Y.W. Lee, Chlorella vulgaris extract ameliorates carbon tetrachloride-induced acute hepatic injury in mice, Experimental and Toxicologic Pathology, 65(1-2),2013, 73-80.

[11] P.Abraham, Oxidative stress in paracetamol-induced pathogenesis: (I). Renal damage, Indian journal of biochemistry \& biophysics,42(1),2005, 59-62.

[12] W.Bernal, G. Auzinger, A. Dhawan, and J. Wendon,Acute liver failure,Lancet, 376, 2010, $190-201$.

[13] C.Srinivasan, W.M. Williams, M.B. Ray, and T.S. Chen, Prevention of acetaminophen-induced liver toxicity by 2(R,S)-n-propylthiazolidine-4(R)-carboxylic acid in mice,Biochemical pharmacology, 61(2), 2001, 245-252.

[14] A. Ramachandran, M. Lebofsky, S.A. Weinman, and H. Jaeschke, The impact of partial manganese superoxide dismutase (SOD2)-deficiency on mitochondrial oxidant stress, DNA fragmentation and liver injury during acetaminophen hepatotoxicity, Toxicology and Applied Pharmacology, 251(3), 2011, 226-233.

[15] M.R. McGill, M.R. Sharpe, C.D. Williams, M. Taha, S.C. Curry, and H. Jaeschke, The mechanism underlying acetaminophen-induced hepatotoxicity in humans and mice involves mitochondrial damage and nuclear DNA fragmentation, The Journal of clinical investigation, 122(4), 2012, 1574-1583.

[16] C.M. Kuo, J.F. Jian, T.H. Lin, Y.B. Chang, X.H. Wan, J.T. Lai, J.S. Chang, C.S. Lin, Simultaneous microalgal biomass production and $\mathrm{CO}_{2}$ fixation by cultivating Chlorella sp. GD with aquaculture wastewater and boiler flue gas, Bioresource Technology, 221, 2016, 241-250.

[17] C.Y. Kao, T.Y. Chen, Y.B. Chang, T.W. Chiu, H.Y. Lin, C.D. Chen, J.S. Chang, C.S. Lin, Utilization of carbon dioxide in industrial flue gases for the cultivation of microalga Chlorellasp,Bioresource Technology, 166,2014, 485-493.

[18] P.Cunniff,Official methods of analysis of AOAC International(Arlington, VA: AOAC International, 1995).

[19] M.Dubois, K.A. Gilles, J.K. Hamilton, P.A. Rebers, and F. Smith, Colorimetric method for determination of sugars and related substances,Analytical Chemistry, 28(3), 1956,350-356.

[20] G.Kochert, J.A. Hellebust, and J.S. Craigie, Quantitation of the macromolecular components of microalgae,in J.A.Hellebust, and J.S Craigi(Ed.), Handbook of Phycological Methods: Physiological and Biochemical Methods, (London: Cambridge University Press, 1978) 189-195.

[21] A.R. Wellburn, The spectral determination of chlorophylls a and b, as well as total carotenoids, using various solvents with spectrophotometers of different resolution,Journal of Plant Physiology, 144(3), 1994, 307-313.

[22] Rut, M. Determination of nucleic acids in yeast. Kvasnýprůmysl. 19(6), 1973,131-133.

[23] Aebi, H. Catalase in vitro. Methods in enzymology, 105, 1984, 121-126.

[24] J. Lu, D.F. Ren, J.Z. Wang, H. Sanada, and Y. Egashira, Protection by dietary Spirulinaplatensis against D-galactosamineand acetaminophen-induced liver injuries, British Journal of Nutrition, 103, 2010, 1573-1576.

[25] H. Jaeschke, T.R. Knight, and M.L. Bajt, The role of oxidant stress and reactive nitrogen species in acetaminophen hepatotoxicity, Toxicology letters, 144(3), 2003, 279-288.

[26] H. Jaeschke, M.R. McGill, and A. Ramachandran, Oxidant stress, mitochondria, and cell death mechanisms in drug-induced liver injury: lessons learned from acetaminophen hepatotoxicity, Drug metabolism reviews, 44(1), 2012, 88-106. 